\title{
Akut Aşil tendon yaralanmasında cerrahi yaklaşım
}

\author{
Surgical approach to acute Achilles tendon injury
}

\author{
Semih Ayanoğlu, Barış Gülenç \\ Medipol Üniversitesi Tıp Fakültesi, Ortopedi ve Travmatoloji Anabilim Dalı, İstanbul
}

\begin{abstract}
Aşil tendonu vücudumuzun en güçlü ve kalın tendonu olmasına rağmen, yaralanmaları sıklıkla sakatlık ile sonuçlanır giderek de yaygınlaşan bir yaralanmadır. Akut Aşil tendon rüptürü olan hastalar için tedavi protokolleri sürekli olarak modifiye edilmektedir. Hem cerrahi hem de cerrahi olmayan tedaviler, alçı veya ortez kullanarak immobilizasyondur. Bununla birlikte, bazı randomize çalışmalara rağmen, optimal tedavi protokolüne ilişkin bir fikir birliği yoktur. Meta-analizler genellikle, cerrahi olarak tedavi edilen hastalara göre konservatif tedavi uygulanan hastalarda yeniden kopma oranının daha yüksek olduğunu (\%3,5'e karşılık \%12,6) kabul etmektedir. Cerrahi olarak tedavi edilen hastalar, enfeksiyonlar, yara problemleri ve sinir yaralanmaları gibi diğer komplikasyonlar açısından daha fazla riske maruzdurlar. Ayrıca, tedavi tipine bakılmaksızın, hastalar genellikle Aşil tendon kopması sonrası devam eden zayıflık ve azalmış işleve sahiptirler. Akut Aşil tendon rüptürü olan hastalarda kullanılan tedavi protokollerinde büyük farklılıklar vardır. İlk karar, tedavinin cerrahi mi yoksa konservatif mi olması gerektiğidir. Cerrahi seçilirse, literatür hem açık hem de perkütan onarımları içeren birçok farklı tekniği sunmaktadır. Tüm bilinenlere rağmen, hangi yaklaşımın optimal olduğu hala netlik kazanmamıştır.
\end{abstract}

Anahtar sözcükler: akut Aşil tendon yaralanması; minimal invaziv cerrahi; perkütan tamir
Achilles tendon injuries are a widespread injury that often results in disability despite being the strongest and thickest tendon of the body. Treatment protocols for patients with acute Achilles tendon rupture are constantly being modified. Both surgical and nonsurgical therapies are followed by immobilization in a cast or a movable brace. However, despite several randomized studies, there is no consensus regarding the optimal treatment protocol. Meta-analyses generally agree that the re-rupture rate in patients treated non-surgically $(12.6 \%)$ is higher than in patients treated surgically (3.5\%). Surgically treated patients have an increased risk of other complications such as infections, wound problems, and nerve injuries. Furthermore, regardless of treatment type, patients often have residual weakness and decreased function after Achilles tendon rupture. There are great variations in the treatment protocols used for patients with acute Achilles tendon rupture. The initial decision is whether treatment should be surgical or nonsurgical. If surgery is chosen, the literature describes many different techniques that include both open and percutaneous repairs. Despite all well-known facts, it is still unclear which approach is optimal.

Key words: acute Achilles tendon rupture; minimal invasive surgery; percutaneous repair

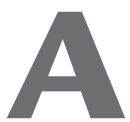

kut Aşil tendon yaralanması sıklıkla $(<3$ hafta) alt ekstremitede ve tipik olarak gastroknemius-soleus tendon kompleksinin midsubstance tendinöz kısmında görülür. Aşil tendon, kalkaneus yapışma 2-6 cm proksimalindeki bölgede en küçük kesit alanına sahiptir ve rüptürlerin en sık görüldüğü yer bu bölgedir.[1] Rüptürden önce, olguların yaklaşık \%10'unda prodromal semptomlar gelişir. Anatomik dağılımlarına bakıldığında; en az görülen proksimal bölge kopmaları \%4-14'ünü, en çok görülen orta bölüm 2-6 cm kalkaneous proksimalindekiler yaklaşık \%75'ini (\%72-73) ve son olarak en distal bölgedekiler de \%14-24'ünü oluşturur. ${ }^{[2]}$ Akut Aşil tendon yaralanmaları, 30-49 yaş aralığında amatör sporcularda sık görülen bir yaralanmadır. ${ }^{[3]}$ Son yıllarda yapılan çalışmalar, akut yaralanma sıklığının 49-60 yaş aralığında arttığını, ancak cerrahi işlem rakamlarının azaldığını göstermektedir. ${ }^{[4]}$ Aşil tendonunun akut yaralanması, en sık top veya raket oyunları gibi yüksek darbeli (highimpact) sporlarda görülür. ${ }^{[4-10]}$ Yaralanma mekanizması üç kategoriye ayrılmıştır ${ }^{[11,12]}$ :

- Illetişim adresi: Doç. Dr. Semih Ayanoğlu, TEM Avrupa Otoyolu Göztepe Çııışı, No: 1 Bağcılar, 34214 İstanbul Tel: 0532 - 3221037 e-posta: semihayanoglu@gmail.com

- Geliș tarihi: 1 Ocak $2018 \quad$ Kabul tarihi: 1 Ocak 2018 
1. Diz ekstansiyon pozisyonunda, güçlü parmak ucuna kalkma (en yaygın).

2. Ayak bileğinin ani dorsifleksiyonu.

3. Plantarfleksiyon pozisyonundaki ayağın şiddetli dorsifleksiyonu.

Gelişmekte olan fonksiyonel ortezler ve erken harekete izin veren tedavi protokolleri sayesinde, konservatif tedavi sonuçları değerlendirildiğinde, yeniden kopma ve fonksiyonel sonuçların cerrahi tedaviden çok farklı olmadığı, bununla beraber komplikasyon oranının düşük olduğu görülmüşsürr. ${ }^{[13]}$ Son yıllarda, konservatif tedaviyi destekleyen kanıtlar eşliğinde, Finlandiya gibi bazı ülkelerde Aşil tendon kopmalarında cerrahi yaklaşım oranları \%55'e varan oranlarda azalma göstermiştir. ${ }^{[14]}$ Doğru tedavi yöntemini seçerken; yeniden kopma riski, cilt ve sinir komplikasyonları, tamir sonrası plantar fleksiyon gücü ve işe dönüş süresi gibi parametreler göz önünde bulundurulmalıdır.

Cerrahi tedavi seçenekleri; açık cerrahi, minimal invaziv ve perkütan tamir tekniklerini içermektedir. Tedavinin temel amacı, fizyolojik tendon uzunluk ve gerginliğinin restorasyonu ve nihai olarak kas gücü ve fonksiyonunun geri kazanılmasıdır. Trombositten zengin plazma (PRP) ve kemik iliği kaynaklı kök hücre tedavileri gibi biyolojik destek ürünler kullanılarak yapılan uygulamalarda, post-op tendon iyileşmesi üzerine henüz anlamlı bir etki elde edilememiştir.

\section{TANI VE DEĞERLENDIRME}

Akut Aşil tendon kopmalarının \%20-25'i başlangıçta yanlış teşhis edilmektedir. ${ }^{[15-17]}$ Kapsamlı bir fizik muayene ve öykü alınması çok önemlidir. Hastalar ayak bileği arkasında ağrı ve ayak bileğinin arkasına vurulduğu veya tekmelendiği hissini bildirir. Çoğu zaman kırbaç veya patlama sesi duyduklarını ifade ederler. Çoğu hasta etkilenmiş bacağa tam ağırlık veremez. Bununla birlikte, bazı hastalar çok az acı tarif eder ve yürüme yeteneğini kaybetmezler. Akut yaralanma sonrası yapılan klinik muayenede tipik olarak ödem, morluk ve sıklıkla tendonun kalkaneous yapışma yerinden yaklaşı $3-5 \mathrm{~cm}$ proksimalinde palpe edilebilir bir boşluk görülür. Birçok hasta, ikincil kasları (fleksör hallusis longus, fleksör dijitorum longus, posterior tibialis ve peroneal kaslar) kullanarak ayak bileğini aktif olarak plantar fleksiyona getirebilir. Simmonds-Thompson testi, hasta prone pozisyonda ve diz fleksiyon postüründe baldır sıkarak yapılır. Bu test, soleus muskülotendinöz ünitenin bütünlüğünü değerlendirir. Sağlam olgularda, ayak bileği plantar fleksiyona gelir. ${ }^{[18]}$ Tendon yırtıldığında, ayak bileği plantar fleksiyona gelemez. Bu test 0,96 duyarlılık ve 0,93 özgüllük göstermiştir. ${ }^{[16]}$

Amerikan Ortopedi Cerrahları Akademisi'nin (American Academy of Orthopaedic Surgeons -AAOS) Aşil tendon rüptürleri hakkındaki klinik uygulama kılavuzları, ayrıntılı bir öykü ve fizik muayenenin yapılmasını ve tanı için aşağıdaki testlerden en az ikisini içermesi gerektiğini bildirmektedir ${ }^{[19]}$ :

\section{PozitifThompson testi.}

2. Ayak bileği plantarfleksiyon gücü azalması.

3. Palpe edilebilen boşluğun varlığı.

4. Hafif manipülasyon ile artan pasif ayak bileği dorsifleksiyonu.

Garras ve ark., tam kopuk tanısı için \%100 duyarlılığa sahip üç fizik muayene bulgusunun kombinasyonunu tanımlamışlardır: Thompson testinde pozitif sonuç, yüzüstü pozisyonda ayak bileği istirahat gerginliğinin, diz $90^{\circ}$ fleksiyonda iken karşı tarafla karşılaştırıldığında, azalmış olması (Matles testi) (normal plantarfleksiyon $20^{\circ}-30^{\circ}$ ) ve Aşil tendonda palpe edilebilen bir defekt olmasıdır. ${ }^{[8]}$

\section{GÖRÜNTÜLEME}

Aşil tendon yaralanmalarını teşhis etmek için, düz radyografi, manyetik rezonans (MR) görüntüleme ve ultrasonografi (US) gibi çoklu görüntüleme yöntemleri kullanılır. Her testin kendine özgü avantajları ve dezavantajları vardır.

İngiltere'de Aşil tendon rüptürlerinin teşhisi için US yaklaşık olarak dört kat daha fazla kullanılmaktadır. ${ }^{[20]}$ US'nin avantajları; ucuz olması, çoğu hastanede kolayca bulunabilmesi, hızlı, tekrarlanabilir olması ve tendonun dinamik olarak değerlendirilmesine olanak sağlamasıdır. US, tendonun kalınlığını ve total kopmada tendonun uçları arasındaki boşluğu değerlendirmede etkilidir; dinamik incelemeye izin verir ve tedavi takibinde etkin olarak kullanılır. Dezavantajlar operatöre bağımlıdır ve kısmi yırtılmalarda MR kadar etkili değildir. Kayser ve ark., US'de Aşil tendonunun proksimal kısmi yaralanmalarını saptamak için duyarlılığın 0,5 ve özgüllüğün 0,81 olduğunu bildirmişlerdir. ${ }^{[21]}$ Türkiye'de genellikle Aşil tendonunun akut yaralanmalarını teşhis etmek için en yaygın görüntüleme aracı MR'dir.

\section{Aşil Tendon Rüptür Skoru (Achilles Tendon Rupture Score-ATRS)}

Aşil tendon yaralanması olan hastalar için sonuçların değerlendirilmesi, subjektif parametrelerin bir karışımına dayanır. ATRS ilk olarak 2007 'de onaylanmış, 
hastaya yönelik bir değerlendirme aracına ihtiyaç duyulduktan sonra geliştirilmiştir. ${ }^{[22]}$ ATRS'nin yüksek düzeyde güvenilirlik, geçerlilik, duyarlılık ve iç tutarlılığa sahip olduğu kanıtlanmıştır. ${ }^{[23,24]}$ ATRS cerrahlara, Aşil tendon rüptürü sonrası fonksiyonel sonuçları değerlendirmek için en iyi aracı sağlamaktadır. Tek ayak parmak ucu kalkma yeteneği, hasta bildirilen sonuç ölçütleri (Patient Reported Outcome Measures) ile ilişkilidir, ancak bu sonuç literatürde geniş bir şekilde rapor edilmemiştir. ${ }^{[25]}$

\section{CERRAHI TEDAVi}

Aşil tendon yaralanması tamiri için geleneksel insizyon, hasta prone pozisyonda midline posterior insizyondur. Taylor ve Palmer 1987'de, bu bölge tibialis posterior ve peroneal arterlerin bileşke bölgesi olduğu için, en düşük cilt komplikasyon riskinin midline yaklaşımda olduğunu belirtmişlerdir. ${ }^{[26]}$ Ancak, Yepes ve ark. yapmış oldukları kadavra çalışmasın$\mathrm{da}$, Aşil tendon çevresi dijital damarlanma haritalarını çıkarmışlar, cilt ve subkutan vasküler ağın en yoğun ve cilt komplikasyon riskinin en düşük olduğu bölgenin Aşil tendon mediyal ve lateral'i olduğunu bulmuşlardır. ${ }^{[27]}$ Posteromediyal insizyon, sural sinir yaralanma riski az olması nedeniyle tercih edilmektedir. Posteromediyal insizyon cerraha supin ve prone pozisyonda çalışma olanağı verir. Literatüre bakıldığında, posterior ve posteromediyal insizyon arasındaki cilt komplikasyon oranları karşılaştırıldığında (\%7 ve \%8,3) aralarında belirgin bir fark olmadığı görülmektedir. ${ }^{[28]}$ Bruggeman ve ark. çalışmalarında risk faktörlerini sigara, steroid kullanımı ve kadın cinsiyet olarak saptamışlar, ancak diyabet, yaş ve vücut kitle endeksi ile istatistiksel olarak anlamlı bir ilişki bulamamışlardır. ${ }^{[29]}$

\section{Açık Aşil Tendon Tamiri (Klasik Primer Onarım)}

Hasta yüzüstü pozisyondadır ve hemostaz için bir uyluk turnike kullanılır. Karşı ekstremite, ameliyat sırasında triseps surae kası istirahat gerginliğini değerlendirmek için steril örtülür. Aşil tendonun $0,5 \mathrm{~cm}$ mediyalinden longitudinal insizyon $(5-7 \mathrm{~cm})$ yapılır. Cilt komplikasyonlarından kaçınmak için özenli çalışılır. Cilt altı keskin disseksiyon yapılarak, paratenona ulaşılarak açılır, tendon uçlarına ulaşılır. Ayak bileği ekine alınarak tendon uçları yaklaştırılır ve hematom debride edilir. Modifiye Kessler, Bunnell veya Krackow tekniği kullanılarak, tendon uçları emilmeyen sütür ile yaklaştırılır. ${ }^{[30]}$ Paratenon ve cilt, anatomik olarak kapatılır. Onarım güçlü değilse tel sütür kullanılabilir. ${ }^{[31,32]}$ Onarımı güçlendirmek için, epitendinöz küçük emilebilir sütürler kullanılarak güçlendirilir. Tendon onarımı yetersiz olgularda, turn-down fasya grefti, plantaris tendonu, FHL veya peroneus brevis tendon transferi yapılabilir (Şekil 1). Literatür, Aşil tendonun akut basit rüptürlerinde, onarımı destekleyen ek işlemlere ihtiyaç olmadığını göstermektedir. ${ }^{[33]}$

\section{Perkütan Aşil Tendon Tamiri}

1977 yilında Ma ve Griffith, cilt komplikasyon oranlarını düşürmek için geliş̧irdikleri perkütan sütür tekniğini kullanarak, küçük insizyon ve minimal yumuşak doku hasarı avantajları olan Aşil tendon tamiri sonuçlarını yayımladılar. ${ }^{[34]}$ Tendon boyunca açılan altı adet mini-insizyondan geçirilen emilmeyen sütürler ile, tendon uçlarının görülmeden tamiri gerçekleştirilir (Şekil 2). Geçmiş çalışmalarda sural sinir yaralanması rapor edilirken, güncel çalışmalarda proksimal lateral mini-insizyondan sinirin bulunarak korunmasıyla, cerrahi teknikteki gelişmeler bu komplikasyonun düşük oranda veya nadir görülmesine yol açmıştır. ${ }^{[35,36]}$ Maes ve ark., perkütan teknik ile tedavi edilen akut Aşil tendon yaralanmalı 124 hastalık serilerinde, tüm teknik gelişmelere rağmen sekiz sural sinir hasarı bildirmişlerdir. ${ }^{[37]}$ Perkütan Aşil tendon tamir tekniği, düşük yara komplikasyon ve yeniden kopma oranıyla, açık cerrahide yüksek başarı oranlarına sahiptir.

Lim ve ark.'nın yapmış olduğu ileriye dönük randomize kontrollü çalışmada, perkütan grupta enfeksiyon hiç görülmezken, açık cerrahi grubunda bu \%21'lere varmaktadır $(p=0,01)$. Yeniden kopma oranları, açık tamirde $\% 6$ ve perkütan tamirde $\% 3$ olarak tespit edilmiş, ancak istatistiksel olarak anlamlı bulunmamıştır. Perkütan tamir komplikasyonları olarak, \%9 yara büzüşmesi ve \%6 yapışıklık rapor edilmiştir. ${ }^{[35]}$

Karaninas ve ark., 34 hastalık ileriye dönük randomize kontrollü çalışmalarında, gruplar arası değerlendirmede; işe dönüş zamanlarında, AOFAS (American Orthopedic Foot and Ankle Society) klinik derecelendirme skalası skorları ve hasta memnuniyeti açısından belirgin fark bulunmamıştır. ${ }^{[36]}$ Henriquez ve ark., geriye dönük 32 hastalık serilerinde, açık ve perkütan tendon tamiri yapılan gruplar arasındaki karşılaştırmalarda, plantar fleksiyon gücü, ROM (range of motion), baldır ve ayak bileği çapı ve tek ayak parmak ucu kalkma gücünde (single heel-raise test) fark bulunmamıştır. Açık cerrahi grupta iki yara komplikasyonu ve bir kez yeniden kopma rapor edilmiştir. Ancak, çalışmadaki hastaların \%42'si takipten çıkmıştır. ${ }^{[38]}$ Perkütan tendon tamiri esnasında tendon uçlarının bir araya gelmesini değerlendirmek ve sural siniri korumak için endoskopi kullanılmaya başlanmıştır. Ancak Chiu ve ark., 19 hastalık serilerinde bir ay sürede $\% 10$ hastada sural sinir uyuşukluğu rapor ettiler. 

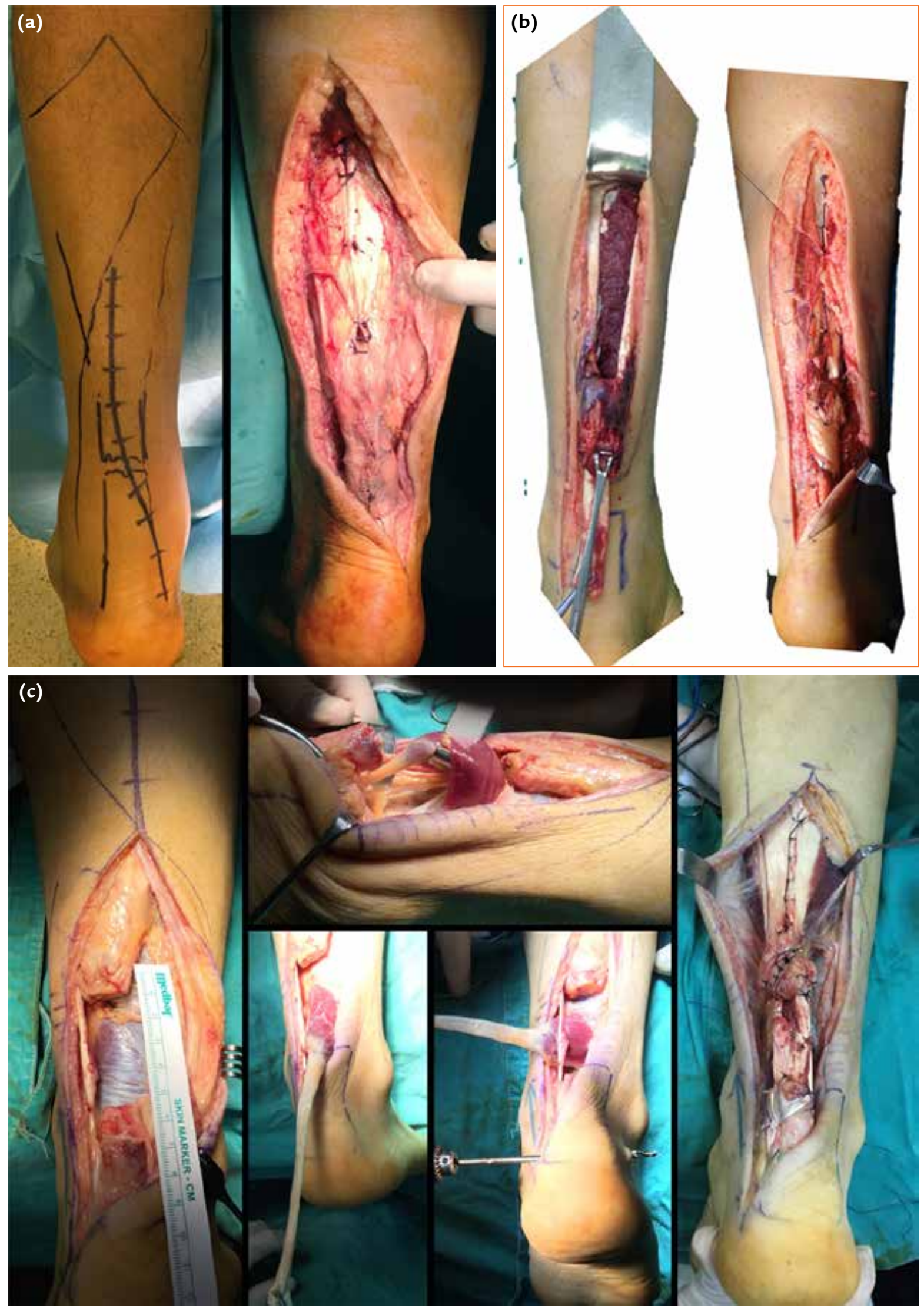

Şekil 1. a-c. V-Y ilerletme Flap \& Hyalonect ${ }^{\circledR}$ Mesh (a). Gastrokinemius turn-down flap (b). FHL tendon transferi (c). 


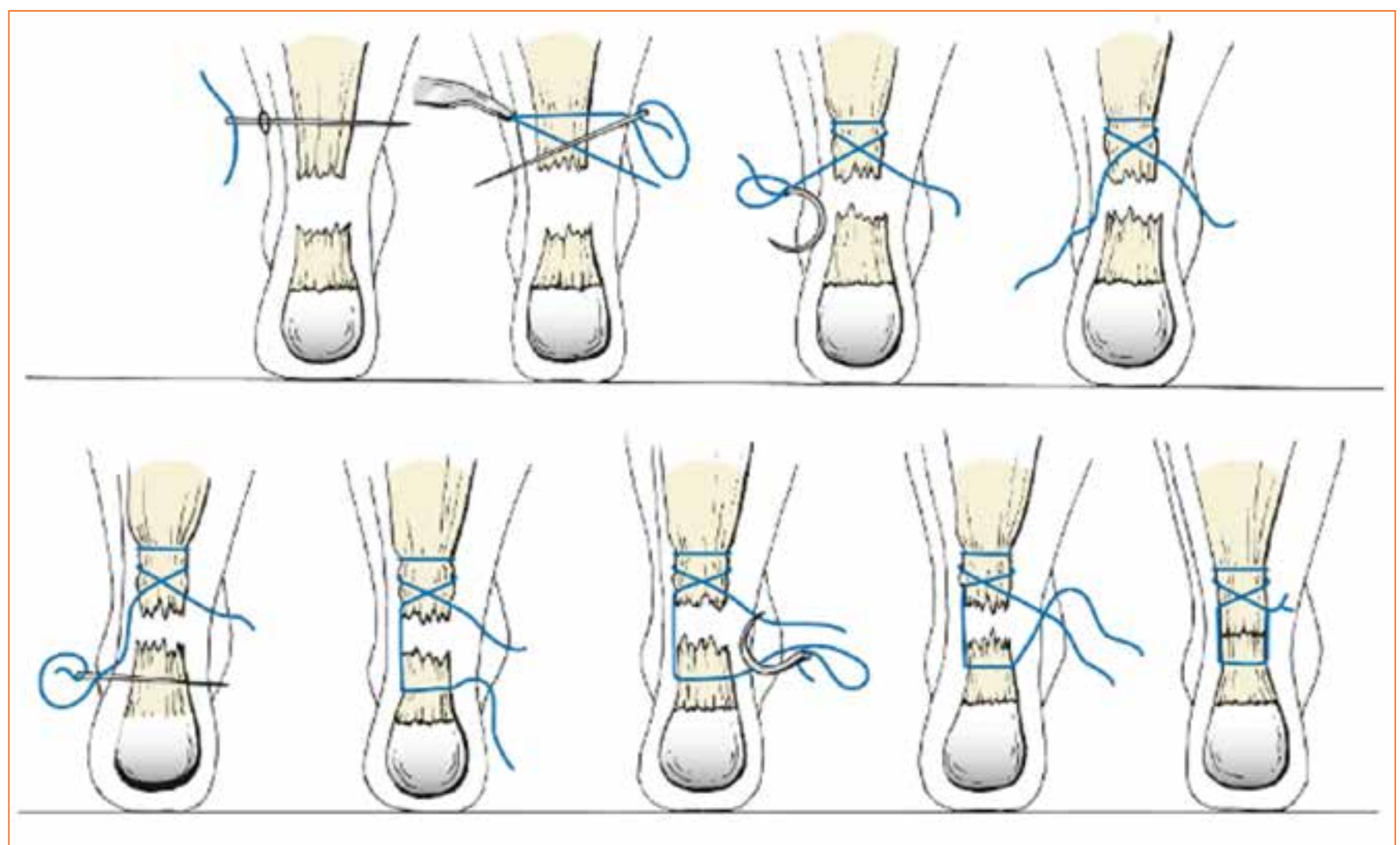

Şekil 2. Aşil tendonu perkütan onarımı. ${ }^{[34]}$

Bunlar, serinin ilk iki olgusuydu ve yazarlar, perkütan cilt kesilerini Aşil tendon lateral kenara yakın açtıkları için diğer hastalarda bu komplikasyonun gelişmediğini bildirdiler. ${ }^{[39]}$

\section{Sınırlı Açık Aşil Tendon Tamiri (Limited Open)}

Perkütan Aşil tendon onarımı, cerrahın son tendon uçlarının bir araya gelmesini veya tamir kalitesini değerlendirmesine izin vermemektedir. Kakiuchi ve ark., tendonun uzunluğunu ve kopan tendon uçlarının temasını en üst düzeye çıkaran, açık ve perkütan teknikleri birleştiren bir teknik geliştirmişlerdir. ${ }^{[40]}$ Bu sınırlı açık teknik, Aşil tendon yaralanma alanında açılan küçük bir insizyon ve paratenon içinden geçen perkütan sütürlerin geçişini basitleştiren modifiye halka forsepsi ile yapılan onarımı içermekteydi (Şekil 3). ${ }^{41]}$ Assal 2002 yılında, "Achillon” Aşil tendon sütür sistemi (Integra Life Sciences Corporation, Plainsboro, NJ) ile, sınırlı açık tamir tekniğiyle tedavi edilen 187 hastalık ileriye dönük çok merkezli bir çalışmada, yara komplikasyonları ya da sural sinir yaralanmaları olmaksızın mükemmel sonuçlar bildirmiştir (Şekil 4). Üç hastada yeniden kopma görülmüştür. Bu hastalardan biri akut düşme sonucu, diğer ikisi uyumsuz post-op ortez kullanımından kaynaklanan Aşil tendon yeniden kopma komplikasyonuydu. ${ }^{[42]}$ Aktaş ve ark., 40 hastalık ileriye dönük randomize çalışmalarında, açık tamir ile "Achillon" sütür sisteminin kullanıldığı mini açık tamir yöntemini karşılaştırdılar. ${ }^{[43]}$ AOFAS skorlarında istatistiksel olarak anlamlı bir fark bulunmadı. Ancak, mini açık tamir grubunda, lokal hassasiyet, cilt adhezyonları, skar ve tendon kalınlığında azalma saptadılar. Her iki grupta da komplikasyon bildirmediler. Yine, Kocaoğlu ve ark.'nın bir başka çalışmasında, emilebilen ve emilmeyen sütürler ile yapılan sınırı açık tamir sonuçları karşılaştırılmış; AOFAS skorları $(98-96,5)$ ve post-op komplikasyon oranları $(\% 0$ $12,5)$ bulunmuş ve emilebilen sütür kullanımı tavsiye edilmiştir. ${ }^{[4]}$ Vadalà ve ark., 36 profesyonel sporcuda, başarılı sınırlı açık Aşil tendon onarımlarına rağmen, 28 aylık takipte kas gücünde $\% 0,94$ azalma, elastikiyette $\% 2,44$ artış ve kondüsyonda $\% 6,78^{\prime}$ lik bir azalma rapor etmişlerdir. ${ }^{[45]}$ Daha geniş tendon görüntülemesine ihtiyaç varsa, uzunlamasına posteromediyal insizyon ile sınırlı açık teknik, tercih edilen tamir yöntemidir. Dikişler, sural sinir hasarı riskini azaltmak için paratenona yakın yerleştirilir. Bu yöntemle, tendon onarımını görsel olarak değerlendirme 


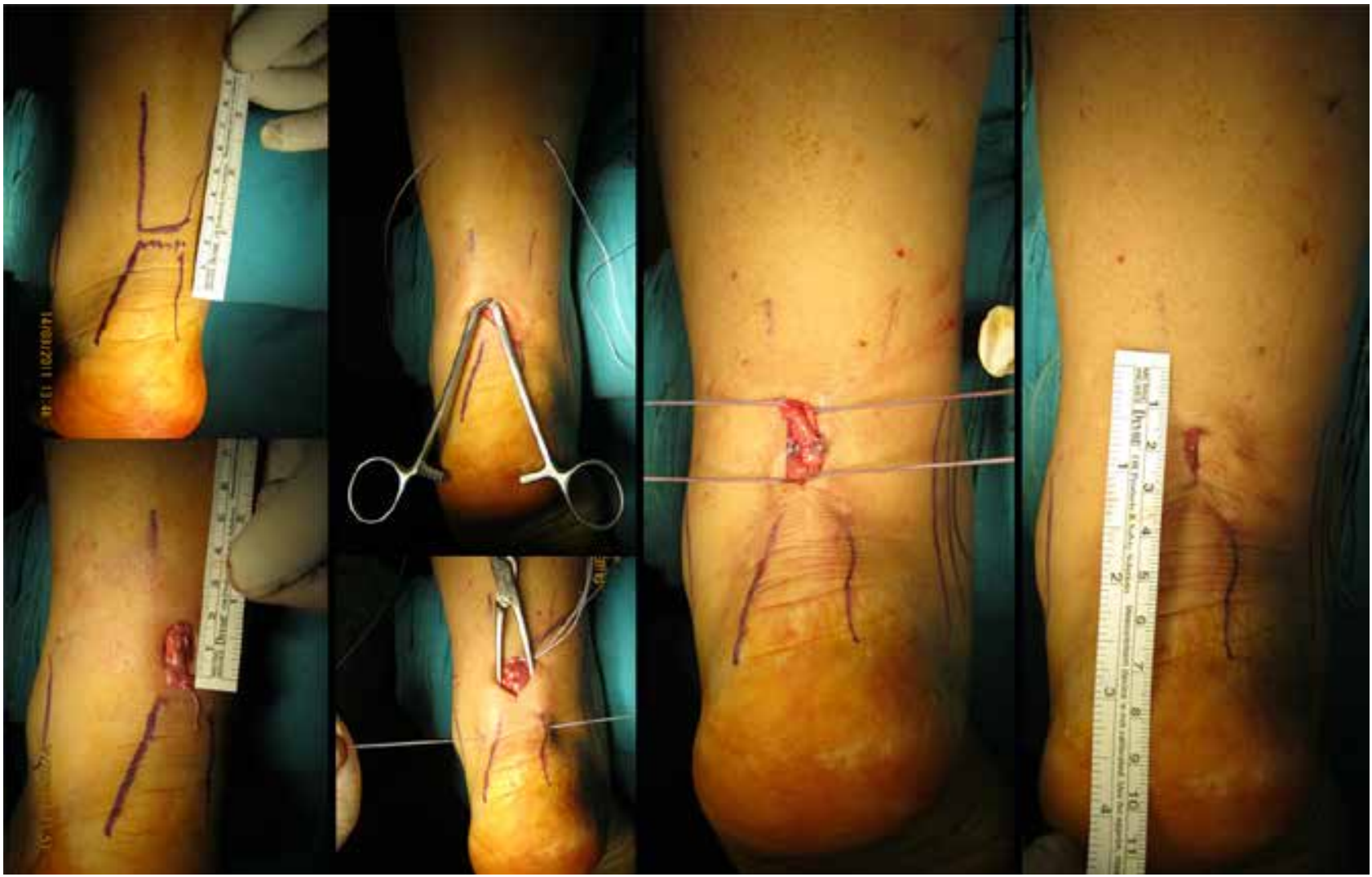

Şekil 3. Sınırı açık Aşil tendon tamiri (ring forceps yardımlı).

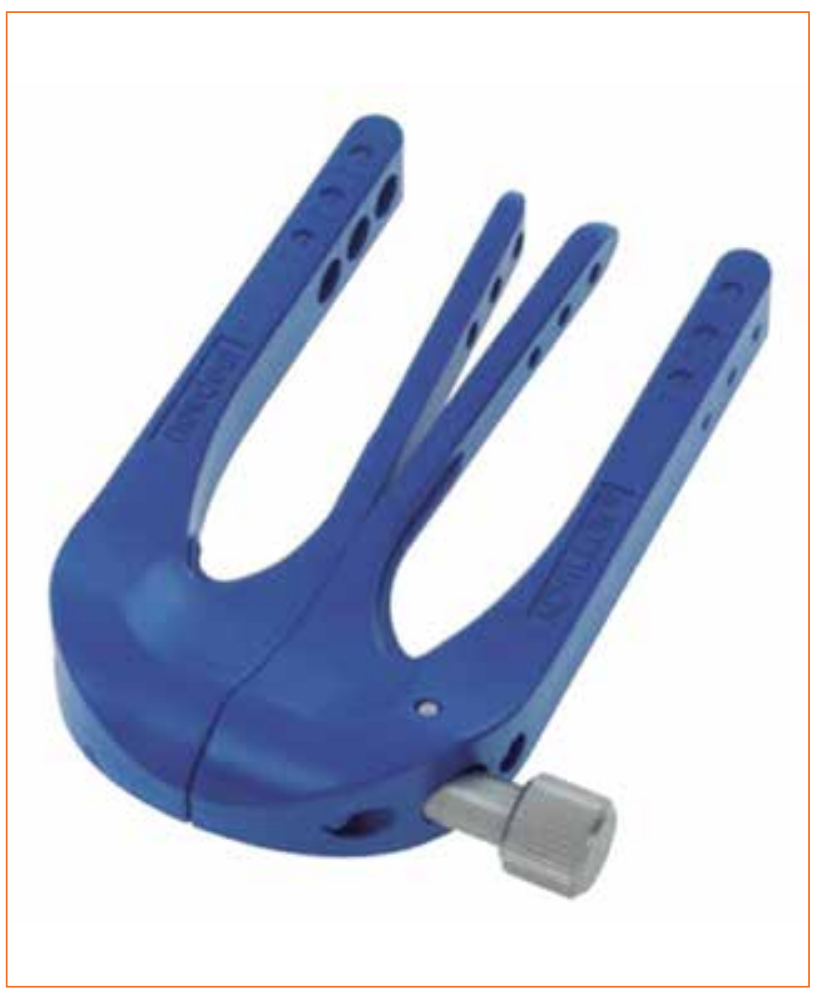

Şekil 4. "Achillon" Aşil tendon sütür sistemi (Integra Life Sciences Corporation, Plainsboro, NJ). daha sağlıklı olmakta, tendon onarım kalitesi ve tendon boyu maksimuma çıkarken, yara komplikasyonlarının azaldığı görülmektedir.

\section{Post-op Protokol}

Klasik Aşil tendon cerrahi onarımından sonra postop tedavi, ağırlık vermeden altı hafta boyunca alçı içinde immobilizasyondan oluşmaktadır. Costa ve ark., 48 hastalık randomize ileriye dönük bir çalışmada, altı hafta alçılı immobilizasyon protokolünü, karbon-fiber ayak bileği ortezi (1,5 cm topuk destekli) ve erken ağırık verilen grup ile karşılaştırmışlardır. Erken ağırlık verilen grupta, normal yürüme ve merdiven tırmanma zamanında kısalma tespit etmişlerdir. Erken ağırlık verilen grupta yer alan iki hastada aktivite kısıtlaması yapmamaları ve düşme sonucu tendon kopması yinelemiştir. Yazarlar, erken yük verilmesi protokolü uygulanacak hastaların seçiminde dikkatli olunmasını, hasta seçiminin önemini vurgulamışlardır ve yük verilmesini önermektedirler. ${ }^{[46]}$ Suchak ve ark., post-op 2. haftada ayak bileğini $20^{\circ}$ ekin pozisyonda tutan menteşeli ayak bileği ortezi (ROM Walker) kullanan hastalardan, erken yük veren ve yük vermeyen iki grubu karşılaştırmışlar; 110 hastada, post-op 6. hafta değerlendirmelerinde, erken yük 
verilen grupta yaşam kalitesinin artması, azalan aktivite kısıtlılığı ile rüptür görülmediğini tespit etmişler; ancak, ameliyat sonrası 6 . ayda gruplar arasında istatistiksel olarak anlamlı fark olmadığını bildirmişlerdir. ${ }^{[47]}$ Literatürde, perkütan Aşil tendon onarımı yapılmış, post-op 2. haftada erken yük vermeye izin verilmiş ve eş zamanlı ROM egzersizi yaptırılan çalışmalarda da benzer sonuçlar elde edilmiştir. Patel ve ark., 52 hastalık serilerinde yeniden kopma görmediklerini rapor etmişlerdir. ${ }^{[48]}$ Hastaların ortalama AOFAS skoru 96'dır ve \%3,8 yüzeysel yara problemi görülmüş ve ikincil cerrahi işlem gerektirmemiştir. Groetelaers ve ark.'nın sınırlı açık Aşil tendon onarımı üzerine yaptıkları çalışmada, post-op 2. haftada korucu ortez kullanan iki grup oluşturulmuştur. Gruplardan birinin yük vermesine izin verilmiştir. Gruplar; kas gücü, hayat kalitesi, işe veya spora geri dönüş süresi açısından değerlendirilmiş; yeniden kopma ve yara enfeksiyonu açısından istatiksel olarak anlamlı fark bulunmamıştır. ${ }^{[49]}$ Önerilen post-op protokol; cerrahi onarımdan sonra cilt ve yumuşak doku iyileşmesine izin vermek için iki haftalık atel veya sirküler alçı ile istirahati takiben, uygun hastalarda ayak bileğini ekinde tutan ve kademeli olarak nötral pozisyona getirebilmeye izin veren çıkarılabilir bir CAM (controlled ankle movement) yürüme botuna geçilmesidir. Hasta, koltuk değnekleriyle ayak tabanı teması ve parsiyel yük vermeye başlar, postop 3. haftada tam yük vermeye geçebilir. Post-op 2. haftadan itibaren, yük vermeden ayak bileği hareket egzersizleri ve denetimli fizik tedavi başlar. Tek ayak parmak ucuna yükselebilen hastaların spor yapmasına izin verilebilir. ${ }^{[50]}$

\section{Biyolojik Ürünler \& Lokal Tamir Güçlendiriciler (PRP, Kemik iliği Kök Hücre, Turn-down Flap vb.)}

Cerrahi sonrası klinik sonuçların iyileştirilmesi ve yeniden kopma oranlarının azaltılması için yapılan araştırmalarda, biyolojik destek ürünleri ve lokal doku tamir destek tedavilerin rolü ve başarıları değerlendirilmiştir. Pajala ve ark., 60 hastalık bir ileriye dönük randomize bir çalışmada, gastrokinemius fasyal "turn-down flap" ile güçlendirilmiş açık Aşil tendonu onarımı tedavisi ile primer tamir sonuçlarını değerlendirmişlerdir. Yeniden kopma oranları, her iki grup için de \%10'dur ve istatistiksel olarak anlamlı bulunmamıştır. Ayrıca, baldır kas gücü, ağrı, ROM ya da işe dönüş zamanlarında da iki grup arasında istatistiksel olarak anlamlı fark yoktur. ${ }^{[33]}$

Akut Aşil tendon onarımlarının sonuçlarını daha iyiye götürme çabaları; PRP veya kemik iliğinden üretilen kök hücre (biyolojik destek ürünleri) tedavilerinin rolünü gündeme getirmiştir. PRP, omuz ve dirseğin spesifik patolojilerinin tedavisinde sınırlı etkinlik göstermesine rağmen, çok az sayıda kanıt akut Aşil tendon rüptürlerinin tedavisinde etkin olduğunu göstermiştir.

Sánchez ve ark., 12 sporcu içeren çalışmalarında, PRP ile ve PRP olmadan açık onarımı karşılaştırmışlardır. PRP grubunda ROM'un daha hızlı toparlandığını ve spora geri dönüşü daha kısa bulmuşlardır. Her iki gruptaki tüm sporcular, bir yıllık takip süresi sonunda spora sorunsuz dönebilmişlerdir. ${ }^{[51]}$ Schepull ve ark., 30 hastalık randomize tek kör çalışmalarında, PRP grubu ile kontrol grubu arasında bir yıllık takipte fonksiyonel sonuç veya mekanik tendon özellikleri açısından bir fark olmadığını bildirmişlerdir. Kemik iliği kaynaklı kök hücreler hayvan modellerinde umut vaat etmektedir, ancak klinik veriler henüz rapor edilmemiş̧tir. ${ }^{[52]}$ Okamoto ve ark., kemik iliği hücreleri veya mezenşimal kök hücrelerin eklenmesiyle ve bunlar olmadan Aşil tendon onarımını karşılaştırmak için, bir sıçan modeli kullandılar. Kemik iliği hücre grubunda, post-op 7., 14. ve 28. günlerde tendon yetmezliğine karşı en yüksek mukavemeti buldular. Buna karşılık, mezenşimal kök hücre grubunda, 7. ve 14. günlerde tendon yetmezliğine karşı daha fazla dayanıklılık göstermesine rağmen 28. günde fark bulunamamıştır. ${ }^{[33]}$ Benzer şekilde, Adams ve ark., sıçanlarda tamir sonrası mezenşimal hücre enjekte edilen grup ile mezenşimal hücreler emdirilmiş sütür kullanılarak tendon tamiri yapılan iki grup oluşturdular. Bu çalışmada, post-op 28. günde tendon tamir yetmezliğine karşı nihai güçte hiçbir fark bulunmamasına karşın, mezenşimal hücreler emdirilmiş sütür kullanılarak yapılan tendon onarım grubunda postop 28. günde tamir başarısızlığına karşı nihai kuvvetin artmış olduğu ve histolojik bulguların da daha iyi olduğu bildirilmiştir. ${ }^{[54]}$ Bu sıçan modelleri umut vermesine rağmen, bu bulguların klinik uygulamaları şu anda bilinmemektedir.

\section{Aşil Tendon Yaralanmasında Venöz Tromboembolizm (VTE)}

Akut Aşil yaralanması sonrası hastalarda, immobilizasyon gerektiren diğer alt ekstremite yaralanmalarına kıyasla açıklanamayan yüksek VTE oranı vardır. ${ }^{[55]}$ İnsidansın \%0,8 ile \%23,5 arasında değiştiği belirtilmektedir. ${ }^{[56,57]}$ Lapidus ve ark., medikal tromboprofilaksi alan veya almayan Aşil tendon tamiri sonrası asemptomatik DVT (derin ven trombozu) oranını \%34-36 olarak gösterdi. ${ }^{[58]}$ Çalışmalar, semptomatik VTE oranını azaltmak için Aşil tendon tamir sonrası düşük moleküler ağırlıklı heparin (LMWH) veya aspirin kullanımının herhangi bir yararı olmadığını göstermektedir. ${ }^{[58-60]}$ 


\section{SONUÇLAR}

Akut Aşil tendon rüptürlerinin cerrahi olmayan tedavisi, fonksiyonel rehabilitasyondan oluşmalıdır. Fonksiyonel rehabilitasyon ile rapor edilen yeniden kopma oranları, standart konservatif tedavi sonuçlarından daha düşüktür. ${ }^{[61,62]}$ Konservatif fonksiyonel rehabilitasyon, post-op komplikasyonları önlerken, cerrahi tedaviye benzer yeniden kopma oranlarını ve sonuçlarını sunmaktadır. Her ne kadar cerrahi tedavi, yara enfeksiyonları da dahil olmak üzere artan komplikasyon riskiyle ilişkili olsa da, yeni minimal invaziv teknikler, yeniden kopma oranlarını arttırmadan komplikasyon riskini azaltmıştır ve cerrahi tedavi seçimini desteklemektedir. Aşil tendon yaralanmaları, fonksiyonel konservatif tedavisi sonrası, cerrahiye göre daha fazla soleus kas atrofisi ve artmış Aşil tendon uzunluğu (19 $\mathrm{mm}$ ) ile sonuçlanmaktadır. Bu yapısal değişiklikler sonucu, konservatif tedavi sonrası baldır kas kuvvetinin azaldığı (\%10-18) gösterilmiştir. ${ }^{[63]}$

Cerrahi tedavinin, işe erken dönüş ve biraz daha plantar fleksiyon gücü sağladığı ve sporcularda göz önünde bulundurulması gerektiği gösterilmiştir. PRP ve kemik iliğinden üretilen kök hücreler gibi biyolojik yardımcı maddelerin, Aşil tendon rüptürlerinin cerrahi tedavisinde henüz kanıtlanmış bir rolü yoktur.

\section{KAYNAKLAR}

1. Strocchi R, De Pasquale V, Guizzardi S, Govoni P, Facchini A, Raspanti M, Girolami M, Giannini S. Human Achilles tendon: morphological and morphometric variations as a function of age. Foot Ankle 1991;12(2):100-4.

2. Coughlin M, Saltzman C, Anderson R. Mann's Surgery of the Foot and Ankle, 9th ed. Elsevier Health Sciences; 2014.

3. Suchak AA, Bostick $G$, Reid D, Blitz S, Jomha N. The incidence of Achilles tendon ruptures in Edmonton, Canada. Foot Ankle Int 2005;26(11):932-6. Crossref

4. Huttunen TT, Kannus P, Rolf C, Fellander-Tsai L, Mattila VM. Acute achilles tendon ruptures: incidence of injury and surgery in Sweden between 2001 and 2012. Am J Sports Med 2014;42(10):2419-23. Crossref

5. Houshian S, Tscherning T, Riegels-Nielsen P. The epidemiology of Achilles tendon rupture in a Danish county. Injury 1998;29(9):651-4.

6. Leppilahti J, Puranen J, Orava S. Incidence of Achilles tendon rupture. Acta Orthop Scand 1996;67(3):277-9.

7. Nillius SA, Nilsson BE, Westlin NE. The incidence of Achilles tendon rupture. Acta Orthop Scand 1976;47(1):118-21.

8. Garras DN, Raikin SM, Bhat SB, Taweel N, Karanjia H. MRI is unnecessary for diagnosing acute Achilles tendon ruptures: clinical diagnostic criteria. Clin Orthop Relat Res 2012;470(8):2268-73. Crossref

9. Nilsson-Helander K, Silbernagel KG, Thomee R, Faxen E, Olsson $\mathrm{N}$, Eriksson BI, Karlsson J. Acute achilles tendon rupture: a randomized, controlled study comparing surgical and nonsurgical treatments using validated outcome measures. Am J Sports Med 2010;38(11):2186-93. Crossref
10. Willits K, Amendola A, Bryant D, Mohtadi NG, Giffin JR, Fowler $\mathrm{P}$, Kean CO, Kirkley A. Operative versus nonoperative treatment of acute Achilles tendon ruptures: a multicenter randomized trial using accelerated functional rehabilitation. J Bone Joint Surg Am 2010;92(17):2767-75. Crossref

11. Longo UG, Petrillo S, Maffulli N, Denaro V. Acute achilles tendon rupture in athletes. Foot Ankle Clin 2013;18(2):319-38. Crossref

12. Arner $O$, Lindholm A. Subcutaneous rupture of the Achilles tendon; a study of 92 cases. Acta Chir Scand Suppl 1959;116(Supp 239):1-51.

13. Chutkan NB. Surgical versus nonsurgical treatment of acute Achilles tendon rupture: a meta-analysis of randomized trials. Orthopedics 2013;36(2):136-7.

14. Mattila VM, Huttunen $T$, Haapasalo $H$, Sillanpaa $P$, Malmivaara A, Pihlajamaki $\mathrm{H}$. Declining incidence of surgery for Achilles tendon rupture follows publication of major RCTs: evidenceinfluenced change evident using the Finnish registry study. $\mathrm{Br} \mathrm{J}$ Sports Med 2015;49(16):1084-6. Crossref

15. Maffulli N. Rupture of the Achilles tendon. J Bone Joint Surg Am 1999;81(7):1019-36.

16. Maffulli $N$. The clinical diagnosis of subcutaneous tear of the Achilles tendon. A prospective study in 174 patients. Am J Sports Med 1998;26(2):266-70. Crossref

17. O'Brien T. The needle test for complete rupture of the Achilles tendon. J Bone Joint Surg Am 1984;66(7):1099-101.

18. Scott $B$, al Chalabi A. How the Simmonds-Thompson test works. J Bone Joint Surgery British Volume 1992;74(2):314-5.

19. Chiodo CP, Glazebrook M, Bluman EM, Cohen BE, Femino JE, Giza E, Watters WC 3rd, Goldberg MJ, Keith M, Haralson RH 3rd, Turkelson CM, Wies JL, Hitchcock K, Raymond L, Anderson S, Boyer K, Sluka P; American Academy of Orthopaedic Surgeons. American Academy of Orthopaedic Surgeons clinical practice guideline on treatment of Achilles tendon rupture. J Bone Joint Surg 2010;92(14):2466-8.

20. Worth N, Ghosh S, Maffulli N. Management of acute Achilles tendon ruptures in the United Kingdom. J Orthop Surg (Hong Kong) 2007;15(3):311-4. Crossref

21. Kayser R, Mahlfeld K, Heyde C. Partial rupture of the proximal Achilles tendon: a differential diagnostic problem in ultrasound imaging. BrJ Sports Med 2005;39(11):838-42. Crossref

22. Nilsson-Helander K, Thomeé R, Grävare-Silbernagel K, Thomeé P, Faxén E, Eriksson BI, Karlsson J. The Achilles tendon Total Rupture Score (ATRS): development and validation. Am J Sports Med 2007;35(3):421-6. Crossref

23. Kearney RS, Achten J, Lamb SE, Parsons N, Costa ML. The Achilles tendon total rupture score: a study of responsiveness, internal consistency and convergent validity on patients with acute Achilles tendon ruptures. Health Qual Life Outcomes 2012;10:24. Crossref

24. Nilsson-Helander K, Grävare Silbernagel K, Thomee R, Faxen E, Olsson N, Eriksson BI, Karlsson J. Acute Achilles tendon rupture: a randomized, controlled study comparing surgical and nonsurgical treatments using validated outcome measures. Am J Sports Med 2010;38(11):2186-93. Crossref

25. Olsson N, Karlsson J, Eriksson BI, Brorsson A, Lundberg M, Silbernagel KG. Ability to perform a single heel-rise is significantly related to patient-reported outcome after Achilles tendon rupture. Scand J Med Sci Sports 2014;24(1):152-8. Crossref

26. Taylor GI, Palmer JH. The vascular territories (angiosomes) of the body: experimental study and clinical applications. BrJ Plast Surg 1987;40(2):113-41.

27. Yepes H, Tang M, Geddes C, Glazebrook M, Morris SF, Stanish WD. Digital vascular mapping of the integument about the Achilles tendon. J Bone Joint Surg Am 2010;92(5):1215-20. Crossref 
28. Highlander P, Greenhagen RM. Wound complications with posterior midline and posterior medial leg incisions: a systematic review. Foot Ankle Spec 2011;4(6):361-9. Crossref

29. Bruggeman NB, Turner NS, Dahm DL, Voll AE, Hoskin TL, Jacofsky DJ, Haidukewych GJ. Wound Complications after Open Achilles Tendon Repair: an analysis of risk factors. Clin Orthop Relat Res 2004;(427):63-6.

30. Krackow KA, Thomas SC, Jones LC. A new stitch for ligament-tendon fixation. Brief note. J Bone Joint Surg Am 1986;68(5):764-6.

31. Ralston EL, Schmidt ERJr. Repair of the ruptured Achilles tendon. J Trauma 1971;11(1):15-21.

32. Quigley TB, Scheller AD. Surgical repair of the ruptured Achilles tendon. Analysis of 40 patients treated by the same surgeon. Am J Sports Med 1980;8(4):244-50. Crossref

33. Pajala A, Kangas J, Siira P, Ohtonen P, Leppilahti J. Augmented compared with nonaugmented surgical repair of a fresh total Achilles tendon rupture. A prospective randomized study. J Bone Joint Surg Am 2009;91(5):1092-100. Crossref

34. Ma GW, Griffith TG. Percutaneous repair of acute closed ruptured achilles tendon: a new technique. Clin Orthop Relat Res 1977;(128):247-55.

35. Lim J, Dalal R, Waseem M. Percutaneous vs. open repair of the ruptured Achilles tendon -a prospective randomized controlled study. Foot Ankle Int 2001;22(7):559-68. Crossref

36. Karabinas PK, Benetos IS, Lampropoulou-Adamidou K, Romoudis P, Mavrogenis AF, Vlamis J. Percutaneous versus open repair of acute Achilles tendon ruptures. Eur J Orthop Surg Traumatol 2014;24(4):607-13. Crossref

37. Maes R, Copin G, Averous C. Is percutaneous repair of the Achilles tendon a safe technique? A study of 124 cases. Acta Orthop Belg 2006;72(2):179-83.

38. Henriquez H, Muñoz R, Carcuro G, Bastias C. Is percutaneous repair better than open repair in acute Achilles tendon rupture? Clin Orthop Relat Res 2012;470(4):998-1003. Crossref

39. Chiu $\mathrm{CH}$, Yeh WL, Tsai MC, Chang SS, Hsu KY, Chan YS. Endoscopy-assisted percutaneous repair of acute Achilles tendon tears. Foot Ankle Int 2013;34(8):1168-76. Crossref

40. Kakiuchi M. A combined open and percutaneous technique for repair of tendo Achillis. Comparison with open repair. J Bone Joint Surg Br 1995;77(1):60-3.

41. Elton JP, Bluman EM. Limited open achilles tendon repair with modified ring forceps: technique tip. Foot Ankle Int 2010;31(10):914-5. Crossref

42. Assal M. Mini-invasive suture of Achilles tendon ruptures: a concept whose time has come. Rev Med Suisse 2006;2(74):1792-7.

43. Aktas $\mathrm{S}$, Kocaoglu B. Open versus minimal invasive repair with Achillon device. Foot Ankle Int 2009;30(5):391-7. Crossref

44. Kocaoglu B, Ulku TK, Gereli A, Karahan M, Turkmen M. Evaluation of absorbable and nonabsorbable sutures for repair of achilles tendon rupture with a suture-guiding device. Foot Ankle Int 2015;36(6):691-5. Crossref

45. Vadala A, Lanzetti RM, Ciompi A, Rossi C, Lupariello D, Ferretti A. Functional evaluation of professional athletes treated with a mini-open technique for achilles tendon rupture. Muscles Ligaments Tendons J 2014;4(2):177-81.

46. Costa ML, MacMillan K, Halliday D, Chester R, Shepstone L, Robinson AH, Donell ST. Randomised controlled trials of immediate weight-bearing mobilisation for rupture of the tendo Achillis. J Bone Joint Surg Br 2006;88(1):69-77. Crossref

47. Suchak AA, Bostick GP, Beaupré LA, Durand DC, Jomha NM. The influence of early weight-bearing compared with non-weightbearing after surgical repair of the Achilles tendon. J Bone Joint Surg Am 2008;90(9):1876-83. Crossref
48. Patel VC, Lozano-Calderon S, McWilliam J. Immediate weight bearing after modified percutaneous Achilles tendon repair. Foot Ankle Int 2012;33(12):1093-7. Crossref

49. Groetelaers RP, Janssen L, van der Velden J, Wieland AW, Amendt AG, Geelen PH, Janzing HM. Functional Treatment or Cast Immobilization After Minimally Invasive Repair of an Acute Achilles Tendon Rupture: Prospective, Randomized Trial. Foot Ankle Int 2014;35(8):771-8. Crossref

50. Kadakia AR, Dekker RG 2nd, Ho BS. Acute Achilles Tendon Ruptures: An Update on Treatment. J Am Acad Orthop Surg 2017;25(1):23-31. Crossref

51. Sánchez M, Anitua E, Azofra J, Andía I, Padilla S, Mujika I. Comparison of surgically repaired Achilles tendon tears using platelet-rich fibrin matrices. Am J Sports Med 2007;35(2):24551. Crossref

52. Schepull T, Kvist J, Norrman H, Trinks M, Berlin G, Aspenberg P. Autologous platelets have no effect on the healing of human achilles tendon ruptures: a randomized single-blind study. Am J Sports Med 2011;39(1):38-47. Crossref

53. Okamoto $\mathrm{N}$, Kushida $\mathrm{T}$, Oe $\mathrm{K}$, Umeda $\mathrm{M}$, Ikehara $\mathrm{S}$, lida $\mathrm{H}$. Treating Achilles tendon rupture in rats with bone-marrow-cell transplantation therapy.J Bone Joint Surg Am 2010;92(17):277684. Crossref

54. Adams SB Jr, Thorpe MA, Parks BG, Aghazarian G, Allen E, Schon LC. Stem cell-bearing suture improves Achilles tendon healing in a rat model. Foot \& Ankle International 2014;35(3):293-9. Crossref

55. Nilsson-Helander K, Thurin A, Karlsson J, Eriksson BI. High incidence of deep venous thrombosis after Achilles tendon rupture: a prospective study. Knee Surg Sports Traumatol Arthrosc 2009;17(10):1234-8. Crossref

56. Patel A, Ogawa B, Charlton T, Thordarson D. Incidence of deep vein thrombosis and pulmonary embolism after Achilles tendon rupture. Clin Orthop Relat Res 2012;470(1):270-4. Crossref

57. Makhdom AM, Cota A, Saran N, Chaytor R. Incidence of symptomatic deep venous thrombosis after Achilles tendon rupture. J Foot Ankle Surg 2013;52(5):584-7. Crossref

58. Lapidus LJ, Rosfors S, Ponzer S, Levander C, Elvin A, Lärfars G, de Bri E. Prolonged thromboprophylaxis with dalteparin after surgical treatment of achilles tendon rupture: a randomized, placebo-controlled study. J Orthop Trauma 2007;21(1):52-7. Crossref

59. Lassen MR, Borris LC, Nakov RL. Use of the low-molecular-weight heparin reviparin to prevent deep-vein thrombosis after leg injury requiring immobilization. N Engl J Med 2002;347(10):726-30. Crossref

60. Braithwaite I, Dunbar L, Eathorne A, Weatherall M, Beasley R. Venous thromboembolism rates in patients with lower limb immobilization after Achilles tendon injury are unchanged after the introduction of prophylactic aspirin: audit. J Thromb Haemost 2016;14(2):331-5. Crossref

61. Khan RJ, Fick D, Keogh A, Crawford J, Brammar T, Parker M. Treatment of acute achilles tendon ruptures. A metaanalysis of randomized, controlled trials. J Bone Joint Surg Am 2005;87(10):2202-10. Crossref

62. Wallace RG, Heyes GJ, Michael AL. The non-operative functional management of patients with a rupture of the tendo Achillis leads to low rates of re-rupture. J Bone Joint Surg Br 2011;93(10):13626. Crossref

63. Heikkinen J, Lantto I, Flinkkila T, Ohtonen P, Niinimaki J, Siira P, Laine V, Leppilahti J. Soleus Atrophy Is Common After the Nonsurgical Treatment of Acute Achilles Tendon Ruptures: A Randomized Clinical Trial Comparing Surgical and Nonsurgical Functional Treatments. Am J Sports Med 2017;45(6):1395-404. Crossref 